Provided for non-commercial research and educational use only. Not for reproduction or distribution or commercial use.

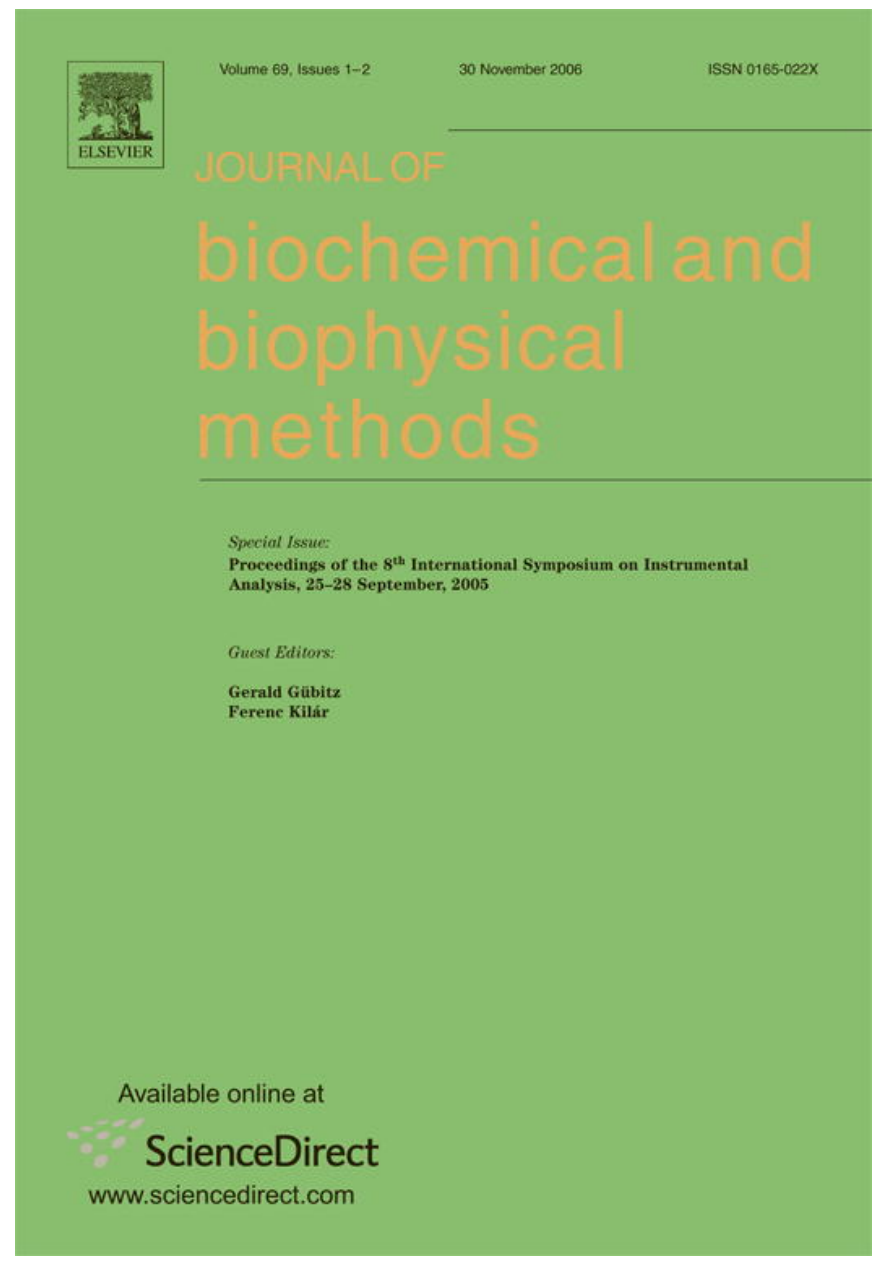

This article was originally published in a journal published by Elsevier, and the attached copy is provided by Elsevier for the author's benefit and for the benefit of the author's institution, for non-commercial research and educational use including without limitation use in instruction at your institution, sending it to specific colleagues that you know, and providing a copy to your institution's administrator.

All other uses, reproduction and distribution, including without limitation commercial reprints, selling or licensing copies or access,

or posting on open internet sites, your personal or institution's website or repository, are prohibited. For exceptions, permission may be sought for such use through Elsevier's permissions site at: 


\title{
Analysis of amino acids and carbohydrates in green coffee
}

\author{
Michael Murkovic*, Karin Derler
}

Graz University of Technology, Institute for Food Chemistry and Technology, Petersgasse 12/2, A-8010 Graz, Austria

Received 12 October 2005; received in revised form 11 January 2006; accepted 9 February 2006

\begin{abstract}
The analysis of carbohydrates and amino acids in green coffee is of the utmost importance since these two classes of compounds act as precursors of the Maillard reaction during which the colour and aroma are formed. During the course of the Maillard reaction potentially harmful substances like acrylamide or 5hydroxymethyl-furfural accrue as well. The carbohydrates were analysed by anion-exchange chromatography with pulsed amperometric detection and the amino acids by reversed phase chromatography after derivatization with 6-amino-quinolyl- $N$-hydroxysuccinimidyl carbamate and fluorescence detection. Both methods had to be optimized to obtain a sufficient resolution of the analytes for identification and quantification. Sucrose is the dominant carbohydrate in green coffee with a concentration of up to $90 \mathrm{mg} / \mathrm{g}$ (mean $=73 \mathrm{mg} / \mathrm{g}$ ) in arabica beans and significantly lower amounts in robusta beans (mean=45 mg/g). Alanine is the amino acid with the highest concentration (mean=1200 $\mu \mathrm{g} / \mathrm{g}$ ) followed by asparagine (mean=680 $\mu \mathrm{g} / \mathrm{g}$ ) in robusta and $800 \mu \mathrm{g} / \mathrm{g}$ and $360 \mu \mathrm{g} / \mathrm{g}$ in arabica respectively. In general, the concentration of amino acids is higher in robusta than in arabica.
\end{abstract}

(C) 2006 Elsevier B.V. All rights reserved.

Keywords: Green coffee; Carbohydrates; Amino acids

\section{Introduction}

In green coffee the carbohydrates and amino acids are the main components that contribute to the formation of the typical aroma during roasting. Standardized procedures for coffee roasting range from $240^{\circ} \mathrm{C}$ for $6 \mathrm{~min}$ to $270^{\circ}$ for $3 \mathrm{~min}$. Industrial coffee roasting is done at higher temperatures. Using these conditions many reactions take place not only forming the aroma and

\footnotetext{
* Corresponding author. Tel.: +43 316 8736495; fax: +43 3168736971.

E-mail address: michael.murkovic@tugraz.at (M. Murkovic).
} 
colour but also undesirable substances like acrylamide [1] or substrates for the sulfotransferases (e.g. 5-hydroxymethyl-furfural) that are metabolically activated to carcinogens [2]. For this reason it is necessary to get knowledge about the composition of the precursors that are transformed to potential hazardous compounds. Having this information research can be carried out by optimising the roasting process with respect to a reduced amount of hazardous compounds. Among many available methods using different detection systems (refractive index, light scattering, and mass selective [3-6]) we choose to separate the carbohydrates by anion-exchange chromatography using pulsed amperometric detection. The amino acids were analysed after derivatization with a fluorescence label on a reversed phase column.

The main carbohydrate occurring in green coffee is sucrose $[7,8]$. This is a well known precursor for the formation of acrylamide [9-11]. The second reactant in the formation of acrylamide is asparagine. This amino acid is not dominating in coffee but occurs at relevant concentrations [12].

Both analyses are critical since the chromatographic separation of glucose from galactose is not part of routine analysis. Asparagine is not separated from serine by using the 6-amino-quinolyl- $N$ hydroxysuccinimidyl carbamate as derivatization reagent and a standard elution profile [13-15]. Both methods had to be optimized to obtain sufficient chromatographic resolution for unequivocal identification and quantification of the analytes.

\section{Materials and methods}

\subsection{Chemicals}

All solvents (e.g. methanol, acetonitrile) used were of HPLC quality and the other chemicals of analytical grade. They were purchased from Merck AG (Darmstadt, Germany). Water was distilled twice and further purified using a water purification system (Simplicity, Millipore, Mohlsheim, France). Reagents for amino acid derivatization were purchased from Waters (Milford, UK). Chemicals needed for chromatography of the carbohydrates were purchased from Dionex (Sunnyvale, CA, USA). $\mathrm{NaOH}$ for chromatography was purchased from Mallinckrodt Baker (Deventer, Holland).

\subsection{Sampling}

Green coffee samples were purchased from the Berliner Kaffeerösterei (Berlin, Germany). The samples analysed were of arabica and robusta type originating from different countries (Arabica: Ethiopian Sidamo Virgamo Grade 2, Kenya AA, Zimbabwe AAA+, Indonesian Sumatra Lintong, Indonesian Sulawesi Kalossi, Indian Monsooned Aspinwalls Malabar AA, Yemen Mocca Matari, Costa Rica Tarazzu, Nicaragua Talia Extra SHG, Guatemala SHB, Mexico Maragogype, Galapagos Specialty Finca San Christobal, Papua New Guinea Sigri AA Grade, Hawaii Kona Extra Fancy, Australia Outback Premium Estates extra Fancy, Zambia AA, Indian Plantation A, Mexico Altura, Uganda Organico, Papua New Guinea Sigri C, Honduras SHG, Columbian Excelso, Santos Brazil NY2 17/18 Top, Kuba Turquino Lavado, China Arabica Shenzen, Tanzania n.s., Kenya n.s.; Robusta: Papua New Guinea, Indian parchment, Indian cherry AB, Rwanda, Vietnam, Liberia, Cameroon).

\subsection{Carbohydrate analysis}

Prior to extraction green coffee beans were ground in an IKA A11 analytical mill for $30 \mathrm{~s}$ (IKA, Staufen, Germany) and for obtaining a fine powder in a ball mill for further $20 \mathrm{~min} .100 \mathrm{mg}$ of the coffee powder were mixed with $1 \mathrm{ml}$ water in a $2 \mathrm{ml}$ Eppendorf tube and vortexed for $30 \mathrm{~s}$. 
Then the tube was treated in an ultrasonic bath for $15 \mathrm{~min}$ and centrifuged $(10 \mathrm{~min}, 16000 \times g)$. After centrifugation the pellet was reextracted twice with $500 \mu 1$ water. The pooled supernatants were diluted to $10 \mathrm{ml}$ in water, passed through a $0.45 \mu \mathrm{m}$ membrane and diluted further with water according to the concentrations needed. All analyses were carried out in duplicate.

The method was adapted from [7]. The chromatographic analysis was carried out on a HPLC HP1100 (Agilent, Waldbronn, Germany) using a CarboPac PA20 $(150 \times 3 \mathrm{~mm}, 6.5 \mu \mathrm{m}$, Dionex, Sunnyvale, CA, USA) and a precolumn of the same material $(30 \times 3 \mathrm{~mm})$. For electrochemical detection a HP 1049A (Hewlett Packard, Waldbronn, Germany) equipped with a gold electrode was used in pulsed amperometric mode $\left(\mathrm{P}=0.10 \mathrm{~V}(800 \mathrm{~ms}), \mathrm{P}_{1}=+0.60 \mathrm{~V}(300 \mathrm{~ms}), \mathrm{P}_{2}=-2.00 \mathrm{~V}\right.$ (300 ms).

The separation of the mono- and disaccharides was carried out isocratically with water (18.2 $\mathrm{M} \Omega$ $\mathrm{cm}^{-1}$ ) with a flow rate of $0.45 \mathrm{ml} / \mathrm{min}$. For detection $100 \mathrm{mM} \mathrm{NaOH}$ was added post column at a flow rate of $1 \mathrm{ml} / \mathrm{min}$. After each analysis the column was washed with $300 \mathrm{mM} \mathrm{NaOH}$ for $15 \mathrm{~min}$. For the separation the column was thermostated to $31^{\circ} \mathrm{C}$. The injection volume was $20 \mu \mathrm{l}$.

For identification the retention times were compared with authentic standards (mannitol, arabinose, galactose, sucrose, glucose, mannose, and fructose). The quantification was done by external calibration comparing the integrated peak areas. Due to easy overload of the column by sucrose two different dilutions had to be analysed one was used for sucrose and the higher concentration of the extract for the minor carbohydrates.

\subsection{Amino acid analysis}

For the extraction of the amino acids green coffee beans were ground first in an IKA A11 analytical mill for $30 \mathrm{~s}$ (IKA, Staufen, Germany) and for obtaining a fine powder in a ball mill (Retsch MM2, Haan, Germany) for further $20 \mathrm{~min}$. The extraction was done according to [16]. $200 \mathrm{mg}$ of the green coffee powder were dispersed in $10 \mathrm{ml}$ of $0.1 \mathrm{~N} \mathrm{HCl}$ in an ultrasonic bath for $15 \mathrm{~min}$ and then passed through a $0.45 \mu \mathrm{m}$ membrane filter (Pall GHP Acrodisc Gf, New York, USA). The extract was then further diluted with water to the concentration needed for derivatization. $2.5 \mathrm{mM}$ stock solutions of $\alpha$-amino butyric acid in $0.1 \mathrm{~N} \mathrm{HCl}$ were used as internal standards. To check for complete extraction the samples were re-extracted using the same procedure. No additional amino acids were extracted in the second step.

For derivatization $10 \mu \mathrm{l}$ of the sample and $10 \mu \mathrm{l}$ of the internal standard were buffered to $\mathrm{pH} 8.8$ with borate buffer to a total volume of $80 \mu 1$. The derivatization was initiated by addition of $20 \mu 1$ reagent solution (6-amino-quinolyl- $N$-hydroxysuccinimidyl carbamate, AccQ.Flour, $3 \mathrm{mg} / \mathrm{ml}$ in acetonitrile). The samples were heated to $55^{\circ} \mathrm{C}$ for $10 \mathrm{~min}$ and then analysed by HPLC with fluorescence detection.

The HPLC system (HP 1100, Agilent, Waldbronn, Germany) consisted of a quaternary pump, a vacuum degasser, a thermostated autosampler, a thermostated column department and a fluorescence detector.

Separation of the derivatized amino acids was performed on an AccQ.Tag amino acid analysis column $(150 \times 3.9 \mathrm{~mm}, 4 \mu \mathrm{m}, \mathrm{RP} 18$; Waters, Milford, USA) by gradient elution. Three eluents were used: A $\left(100 \mathrm{ml}\right.$ of the concentrate $\left(148 \mathrm{~g}\right.$ sodiumacetate $\cdot 3 \mathrm{H}_{2} \mathrm{O}$ and $7.06 \mathrm{~g}$ triethylamin were added to 11 of water, the $\mathrm{pH}$ set to 5.70 with $50 \%$ phosphoric acid, and then diluted to $1100 \mathrm{ml}$ ), $\mathrm{B}$ (same composition but $\mathrm{pH}$ set to 6.80), $\mathrm{C}$ (acetonitrile) and $\mathrm{D}$ (water). During the separation the flow rate was set to $1 \mathrm{ml} / \mathrm{min}$. Linear gradient: $0 \mathrm{~min}$ : $90 \% \mathrm{~A}, 90 \% \mathrm{~B} ; 0.5 \mathrm{~min}: 89 \% \mathrm{~A}, 10 \% \mathrm{~B}, 1 \%$ $\mathrm{C}$; isocratic until $17 \mathrm{~min} ; 20 \mathrm{~min}: 88 \% \mathrm{~A}, 10 \% \mathrm{~B}, 2 \% \mathrm{C}$; $30 \mathrm{~min}: 86 \% \mathrm{~A}, 9 \% \mathrm{~B}, 5 \% \mathrm{C} ; 36 \mathrm{~min}: 63 \%$ A, $25 \%$ B, $12 \%$ B, 36.5 min: $0 \%$ A, $87.5 \%$ B, $12.5 \%$ C; 36.8 min: $22 \%$ A, $65.5 \%$ B, $12.5 \%$ C (flow 
set to $1.3 \mathrm{ml} / \mathrm{min}$ ); $40 \mathrm{~min}: 22 \% \mathrm{~A}, 65 \% \mathrm{~B}, 13 \% \mathrm{C}$; $50 \mathrm{~min}: 22 \% \mathrm{~A}, 63 \% \mathrm{~B}, 15 \% \mathrm{C}$; then the column was washed without buffer for $7 \mathrm{~min}$ and reconditioned for another $9 \min (60 \% \mathrm{C}, 40 \% \mathrm{D})$. The column temperature was maintained at $39{ }^{\circ} \mathrm{C}$ and the injection volume was $5 \mu 1$. For detection of the derivatized amino acids the fluorescence of the eluent was measured at $\lambda_{\mathrm{ex}}=250 \mathrm{~nm}$ and $\lambda_{\mathrm{em}}=395 \mathrm{~nm}$ at a photomultiplier gain of 12 .

The amino acids were identified by comparison of the retention times with that of authentic standards. The quantification was based on the external standard method.

\subsection{Validation of the analytical methods}

Both described methods were fully validated, including the determination of the limits of detection (LOD) and quantification (LOQ) for all investigated compounds. Calibration curves were obtained from five different concentrations (in duplicate or 4-fold, respectively, for the lowest and highest concentrations used) versus the peak areas. The linearity of the calibration curves was checked by linearity tests according to Mandel. The suitability of the linear model was verified by the analysis of the residuals [17] software supported (MS-Excel macro VALIDATA) [18]. Furthermore, for the validation of the methods the variances were tested for their homogeneity based on the $95 \%$ and $99 \%$ confidence interval.

Calculations of LOD and LOQ are based on the calibration function. LOD is defined as the lowest concentration of the analyte that can be determined with a S.D. $=5 \%$.

\section{Results}

\subsection{Amino acids}

The resolution of the derivatized amino acids using reversed phase chromatography succeeds when using a gradient with 3 eluents and a washing period without buffer. Especially asparagine

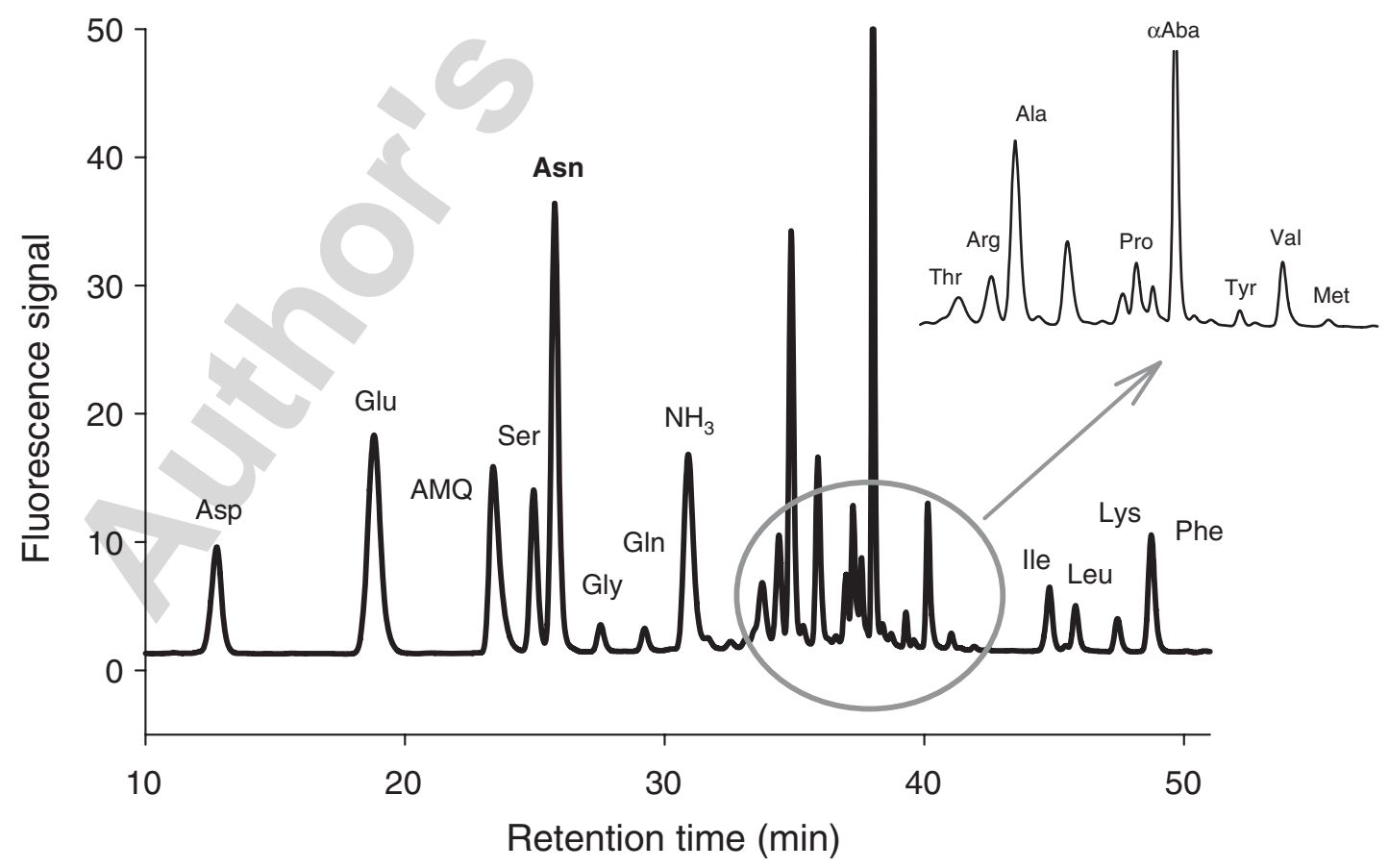

Fig. 1. Chromatogram of amino acids in green coffee. 


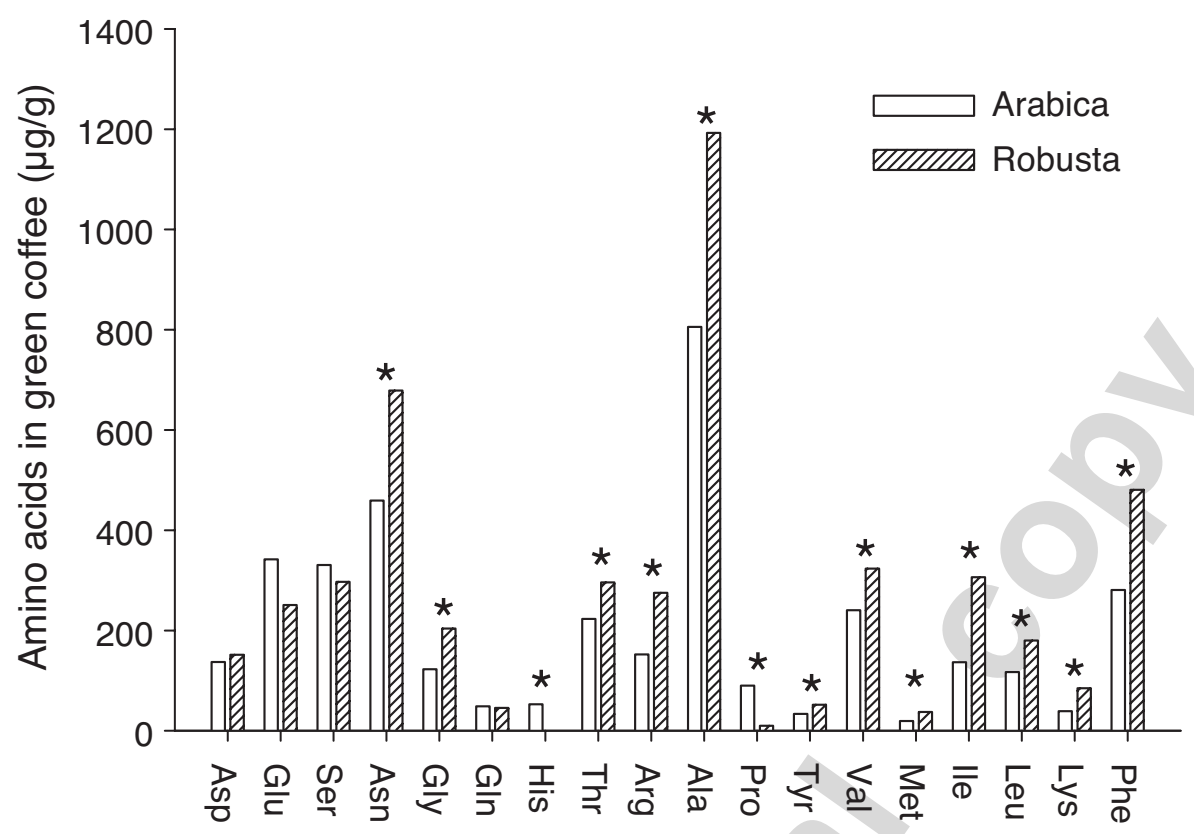

Fig. 2. Comparison of amino acid content of arabica and robusta type green coffee ( $*$ : significant difference).

and serine as well as histidine and glutamine are not resolved using a two eluent gradient (Fig. 1). The temperature of $39^{\circ} \mathrm{C}$ is also critical for a good resolution. The limit of quantification is in the range of $0.1 \mu \mathrm{M}$ for valine and $0.6 \mu \mathrm{M}$ for glutamic acid having a signal to noise ratio of 10 . Due to the importance of asparagine being a precursor of acrylamide this single amino acid was validated. The limit of quantification for the analysis of asparagine was calculated as $0.35 \mu \mathrm{g} / \mathrm{ml}$ $(3 \mu \mathrm{M})$ using a calibration range of 1.0 to $6.5 \mu \mathrm{g} / \mathrm{ml}$.

The content of amino acids in green coffee is in the $\mu \mathrm{g} / \mathrm{g}$ range with alanine having the highest concentration from 410 to $1400 \mu \mathrm{g} / \mathrm{g}$ followed by asparagine ranging from 280 to $960 \mu \mathrm{g} / \mathrm{g}$ and phenylalanine ranging from 180 to $780 \mu \mathrm{g} / \mathrm{g}$ (Fig. 2).

\subsection{Carbohydrates}

The analysis of coffee carbohydrates is critical since under standard conditions not all of the carbohydrates of interest can be separated. For separation pure water was used as eluent giving stable retention times. However, the retention time of sucrose was extremely sensitive to the

Table 1

Limit of detection and quantification of the analysed carbohydrates in green coffee

\begin{tabular}{lclllc}
\hline & $\begin{array}{l}\text { RT } \\
(\mathrm{min})\end{array}$ & $\begin{array}{l}\text { LOD } \\
(\mu \mathrm{g} / \mathrm{ml})\end{array}$ & $\begin{array}{l}\text { LOQ } \\
(\mu \mathrm{g} / \mathrm{ml})\end{array}$ & $\begin{array}{l}\text { LOD in green } \\
\text { coffee }(\mu \mathrm{g} / \mathrm{g})\end{array}$ & $\begin{array}{l}\text { LOQ in green } \\
\text { coffee }(\mu \mathrm{g} / \mathrm{g})\end{array}$ \\
\hline Mannitol & 1.9 & 0.6 & 2.1 & 120 & 420 \\
Fucose & 2.9 & 0.7 & 2.5 & 140 & 500 \\
Arabinose & 6.4 & 0.4 & 1.6 & 80 & 320 \\
Galactose & 7.9 & 0.7 & 2.5 & 140 & 500 \\
Sucrose & 8.4 & 1.1 & 4.0 & 220 & 800 \\
Glucose & 9.3 & 1.1 & 4.0 & 220 & 800 \\
Mannose & 12.2 & 1.7 & 6.1 & 340 & 1200 \\
Fructose & 13.8 & 2.2 & 7.9 & 440 & 1600 \\
\hline
\end{tabular}




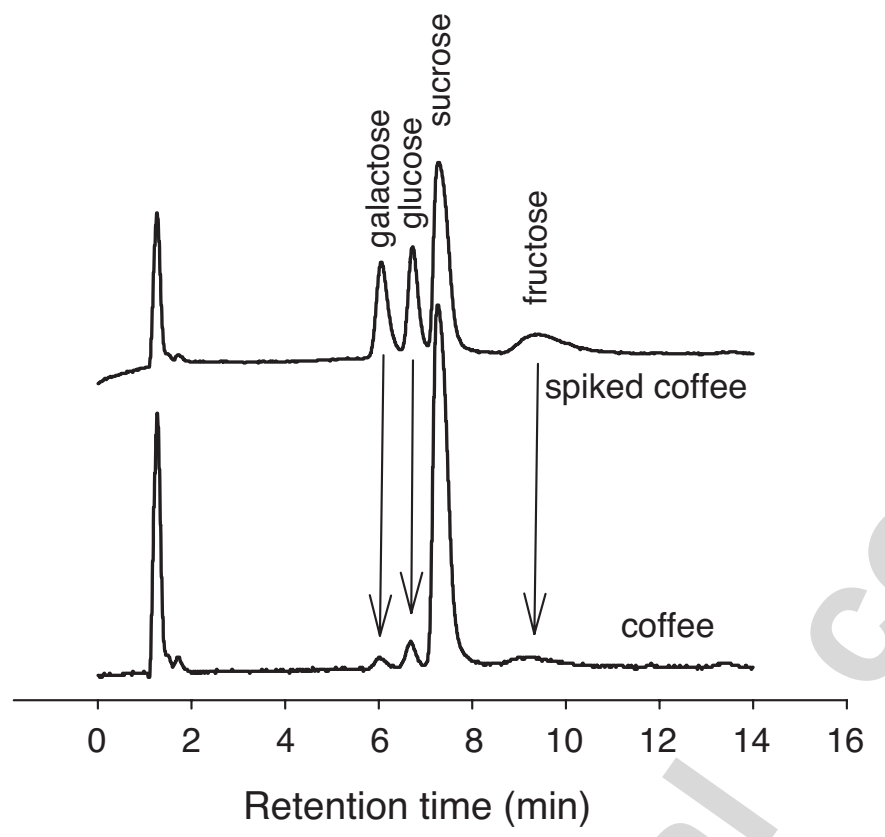

Fig. 3. Chromatogram of simple carbohydrates in green coffee.

column temperature. This effect was used to place the sucrose peak between the minor carbohydrates galactose and glucose.

The detection limits of the tested carbohydrates are in the range of $0.4-2.2 \mu \mathrm{g} / \mathrm{ml}$ which means a minimum detectable amount in green coffee of 80 to $440 \mu \mathrm{g} / \mathrm{g}$ (Table 1) (Fig. 3). Sucrose dominates the carbohydrates with significantly higher concentrations in arabica beans (mean $=73 \mathrm{mg} / \mathrm{g}$ ) compared to robusta beans (mean $=45 \mathrm{mg} / \mathrm{g}$ ). The content of sucrose in the beans is up to $9 \%$ of the total weight which is reacting during the roasting process giving the typical coffee aroma and colour. The other carbohydrates (galactose, glucose and fructose) occur at significantly lower concentrations. Mannitol is only present in arabica beans (Table 2).

\section{Discussion}

The analyses of carbohydrates and amino acids in green coffee were carried out to investigate the occurrence of precursors of the Maillard reaction which is not only responsible for the formation of the typical aroma and colour of roasted coffee but also of potentially harmful substances like acrylamide and 5-hydroxymethyl-furfural. Especially sucrose and asparagine are the two candidates of interest. Sucrose is the dominant carbohydrate which has a concentration of

Table 2

Contents of mono- and disaccharides in green coffee (mg/g d.w.) in arabica and robusta type coffees (n.d.: below LOD)

\begin{tabular}{lll}
\hline & Arabica & Robusta \\
\hline Mannitol & n.d. -0.9 & n.d. \\
Fucose & n.d. & n.d. \\
Arabinose & n.d. & n.d. \\
Galactose & $<0.1-0.6$ & $<0.1-0.6$ \\
Sucrose & $63-90$ & $36-56$ \\
Glucose & n.d. -2.2 & $<0.3-1.6$ \\
Mannose & n.d. & $<0.3$ \\
Fructose & n.d. -1.9 & n.d. -5.9 \\
\hline
\end{tabular}


up to $9 \%$ of the dry weight. The beans of the arabica type contain significant higher concentrations of sucrose. The analysis of the carbohydrates is critical since the carbohydrates other than sucrose occur at comparable low concentrations which made it necessary to analyse two different dilutions - the higher one is used to quantify sucrose and the lower one for the other carbohydrates. Comparison with literature data reveals that other authors have found similar carbohydrate contents in green coffee where $8 \%$ of sucrose arabica and $4 \%$ in robusta are reported [19].

Looking at the amino acids the situation is different. Most of the amino acids occur at higher concentrations in robusta beans. It is interesting to note that the concentration of asparagine is significantly higher in the robusta beans. This is of particular importance since asparagine is the limiting substance of the formation of acrylamide during roasting (unpublished results).

The amino acids that occur at lower concentrations are glutamine, histidine, proline, tyrosine, methionine and lysine. The comparison of arabica and robusta coffees shows that in robusta most amino acids occur at higher concentrations. The concentrations of aspartic acid, glutamic acid, serine, and glutamine are comparable in both types of green coffee. The only amino acid that is higher in arabica is proline.

The comparison of the results of the amino acid analysis with earlier published data show good agreement. However is has to be noted that the amino acid content changes not only during postharvest treatment but also during storage which could be attributed to the Maillard reaction $[20,21]$.

The consequences of these results on the formation of acrylamide and HMF will be investigated in the future.

\section{Acknowledgements}

This study was financed the Commission of the European Communities, specific RTD programme "Food Quality and Safety", QLK1-CT99-01197, "Heat-generated food toxicants Identification, characterisation and risk minimisation". It does not necessarily reflect its views and in no way anticipates the Commission's future policy in this area.

\section{References}

[1] Zyzak DV, Sanders RA, Stojanovic M, Tallmadge DH, Eberhart L, Gruber DK, et al. Acrylamide formation mechanism in heated foods. J Agric Food Chem 2003;51:4782-7.

[2] Glatt HR, Schneider H, Liu Y. V79-hCYP2E1-hSULT1A1, a cell line for the sensitive detection of genotoxic effects induced by carbohydrate pyrolysis products and other food-borne chemicals. Mutat Res 2005;580:41-52.

[3] Guignard C, Jouve L, Bogeat-Triboulot MB, Dreyer E, Haufman JF, Hoffmann L. Analysis of carbohydrates in plants by high-performance anion-exchange chromatography coupled with electrospray mass spectrometry. J Chromatogr A $2005 ; 1085: 137-42$.

[4] Bruggink C, Maurer R, Herrmann H, Cavalli S, Hoefler F. Analysis of carbohydrates by anion exchange chromatography and mass spectrometry. J Chromatogr A 2005;1075:104-9.

[5] Cataldi TRI, Campa C, De Benedetto GE. Carbohydrate analysis by high-performance anion-exchange chromatography with pulsed amperometric detection. Fresenius' J Anal Chem 2000;368:739-58.

[6] Lee YC. Carbohydrate analysis with high-performance anion-exchange chromatography. J Chromatogr A 1996;720:137-49.

[7] Prodolliet J, Bruelhart M, Lador F, Martinez C, Obert L. Determination of free and total carbohydrate profile in soluble coffee. J AOAC Int 1995;78:749-61.

[8] Silwar R, Lüllmann C. The determination of mono- and disaccharides in green arabica and robusta coffees using high performance liquid chromatography. Café Cacao Thé XXXII; 1988. p. 319-22.

[9] Mottram DS, Wedzicha BL, Dosen AT. Acrylamide is formed in the Maillard reaction. Nature 2002;419:448. 
[10] Stadler RH, Robert F, Riediker S, Varga N, Davidek T, Devaud S, et al. In-depth mechanistic study on the formation of acrylamide and other vinylogous compounds by the Maillard reaction. J Agric Food Chem 2004;52:5550-8.

[11] Yaylayan VA, Wnorowski A, Locas CP. Why asparagine needs carbohydrates to generate acrylamide. J Agric Food Chem 2003;51:753-1757.

[12] Arnold U, Ludwig E. Analysis of free amino acids in green coffee beans. II. Changes of the amino acid content in arabica coffees in connection with post-harvest treatment. Eur Food Res Technol 1996;203:379-84.

[13] Cohen SA, Michaud DP. Synthesis of a fluorescent derivatizing reagent, 6-aminoquinolyl-N-hydroxysuccinimidyl carbamate, and its application for the analysis of hydrolysate amino acids via high-performance liquid chromatography. Anal Biochem 1993;211:279-87.

[14] van Wandelen C, Cohen SA. Using quaternary high performance liquid chromatography eluent systems for separating 6-amino-quinolyl-N-hydroxysuccinimidyl carbamate derivatized amino acid mixtures. J Chromatogr A 1997;763:11-22.

[15] Liu HJ, Chang BY, Yan HW, Yu AH, Liu XX. Determination of amino acids in food and feed by derivatization with 6-aminoquinolyl-N-hydroxysuccinimidyl carbamate and reversed-phase liquid chromatographic separation. J AOAC Int 1995;78:736-44.

[16] Kivi JT. Amino acids. In: Nollet LML, editor. Food Analysis By HPLC. New York: Marcel Dekker; 2000. p. 55-97.

[17] DIN 32645m DIN Deutsches Institut für Normung e.V. Berlin: Beuth Verlag; 1994.

[18] Rohrer Ch, Wegscheider W. ValiData, EXCEL-Makro zur Methodenvalidierung, Benutzerhandbuch zu Version 1.01; 1993.

[19] Clark RJ. Green coffee. In: Caballero F, Trugo LC, Finglas PM, editors. Encyclopedia in food sciences and nutrition. London: Academic Press; 2003. p. 1481-7.

[20] Bagdonaite K, Murkovic M. Factors affecting the formation of acrylamide in coffee. Czech J Food Sci 2004;22:22-4.

[21] Arnold U, Ludwig E. Analysis of free amino acids in green coffee beans: II. Changes of the amino acid content in arabica coffees in connection with post-harvest model treatment. Z Lebensm Unters Forsch 1996;203:379-84. 